\title{
STUDI BIBLIKA KORELASI TEOLOGI PAULUS DAN TEOLOGI YAKOBUS TENTANG IMAN DAN PERBUATAN IMAN
}

\author{
Dr. Gidion, M.Th \\ (Dosen prodi Teologi Kependetaan: gideon_JOSILA@yahoo.com)
}

Abstract

There are diverse views within the Christian group about faith and works. Sproul and the Evangelical group with full conviction that the "works" is the fruit or sign of faith. But Peter David and the Pentecostal group have the view that faith together with works produce perfect faith. What Paul and James teach salvation by faith or by works? Or salvation by faith + works? Is it true that the faithful do not care about their moral good or bad? The differences in views between Paul and James about faith and works, some later concluded that there were quarrels in these two figures. This problem then became an important issue to be discussed, because in the history of the church, Martin Luther gave the conclusion that the views of Paul and James about faith and works were indeed contradictory.

\section{A. PENDAhuluan}

Dalam sejarah gereja tampak perdebatan dimanakah sebenarnya posisi Iman dan perbuatan iman. Sproul menyajikan table untuk memperlihatkan perbedaan pandangan ini dalam sejarah keyakinan katholik:

Faith and Works ${ }^{1}$

\begin{tabular}{ll}
\hline Roman Catholic View & Faith + Works $\rightarrow$ Justification \\
\hline Reformation View & Faith $\rightarrow$ Justification + Works \\
\hline
\end{tabular}

Para teolog protestan berulang-ulang menyatakan bahwa konsep pembenaran pada Kanon Trent tidak memberikan penjelasan yang lengkap dan terang benderang mengenai posisi iman dan perbuatan iman. Sproul mengatakan bahwa adalah keliru jika mengatakan bahwa pembenaran diterima oleh karena perbuatan baik, tetapi perbuatan baik merupakan buah atau tanda orang yang memiliki iman. ${ }^{2}$ Jadi Sproul memahami bahwa iman adalah penyebab munculnya perbuatan iman.

Namun pada faktanya ada banyak orang Kristen yang mengklaim bahwa yang diperlukan untuk keselamatan adalah cukup memiliki Iman, perbuatan tidak berarti apa-apa, iman adalah satu-satunya yang paling penting. Paulus menjelaskan bahwa seseorang dibenarkan Allah adalah karena iman, dan bukan karena perbuatan melakukan hukum Taurat (Rom. 3:28). Namun demikian Yakobus seorang soko guru Gereja Yerusalem mengatakan bahwa seseorang dibenarkan bukan hanya karena iman melainkan oleh karena perbuatannya (Yak. 2:24).

Banyak orang yang menolak untuk patuh pada perintah-perintah Allah, namun mereka memiliki keyakinan luar biasa tentang "iman". ${ }^{3}$ Ada beberapa gereja yang mengajarkan bahwa seseorang dapat diselamatkan Allah tanpa perlu menunjukkan bukti hidup yang dibaharui. Mereka mengklaim bahwa Tuhan mengasihi anak-anakNya tanpa perduli apa pun yang dilakukan anak tersebut inilah kasih tanpa syarat, dan mereka meyakini bahwa kasih Tuhan

\footnotetext{
${ }^{1}$ Sproul, R.C.: Faith Alone : The Evangelical Doctrine of Justification. electronic ed. Grand Rapids : Baker Books, 2000, c1995, S. 155

${ }^{2}$ Sproul, R.C.: Faith Alone : The Evangelical Doctrine of Justification. electronic ed., 156.

${ }^{3}$ Ellen G. White, Faith and Works (Washington DC: Ellen G. White Estate, 1979), 47.
} 
tidak didasarkan pada apa pun yang dilakukan manusia. Mereka menyimpulkan bahwa perbuatan baik manusia tidak berarti di hadapan Allah. ${ }^{4}$

Ada juga pandangan yang menyatakan bahwa iman dan perbuatan harus dilakukan secara bersama-sama untuk menghasilkan iman yang sempurna. Peter David mengatakan bahwa pernyataan kebenaran yang sesungguhnya dalam Kejadian 22:12 menunjukkan bahwa iman bukan semata-mata ortodoksi, melainkan keyakinan yang mengarah pada perbuatan yang nyata. Sehingga "iman bekerja sama dengan perbuatan-perbuatan dan oleh perbuatan-perbuatan itu, iman menjadi sempurna" (Yak. 2:22). ${ }^{5}$

Ada pandangan yang beragam dalam kelompok Kristen tentang iman dan perbuatan iman. Sproul dan kelompok Injili dengan penuh keyakinan menyatakan bahwa perbuatan iman adalah buah atau tanda dari iman. Sedangkan Peter David dan kelompok Pentakosta memiliki pandangan bahwa iman bersama-sama perbuatan menghasilkan iman yang sempurna. Apakah Yakobus mengajarkan keselamatan oleh iman atau oleh perbuatan? Atau keselamatan oleh iman + perbuatan? Apakah asal beriman saja tidak peduli moralnya baik atau jahat? Apakah Yakobus bermaksud menambahkan syarat lain yaitu 'perbuatan' ketika ia menyatakan "Bukankah Abraham, bapa kita, dibenarkan karena perbuatan-perbuatannya, ketika ia mempersembahkan Ishak, anaknya, di atas mezbah?" (Yakobus 2:21). Pertanyaan-pertanyaan ini terus menjadi penyebab konflik konsep iman dan perbuatan iman sampai pada saat ini. Ada kelompok Kristen yang dengan keliru telah menghilangkan "perbuatan iman" sebagai penyebab keselamatan. Namun ada juga kelompok Kristen yang meyakini bahwa seseorang diselamatkan melalui perbuatannya. ${ }^{6}$

Perbedaan pandangan Paulus dan Yakobus tentang iman dan perbuatan iman, ada yang kemudian menyimpulkan bahwa terjadi pertengkaran pada kedua tokoh ini. ${ }^{7}$ Masalah ini kemudian menjadi masalah penting untuk dibahas, oleh karena dalam sejarah gereja seorang Marthin Luther memberikan kesimpulan bahwa padangan Paulus dan Yakobus tentang iman dan perbuatan iman memang bertentangan. ${ }^{8}$ Pada tulisannya yang lain Marthin Luther menyebutkan surat Yakobus adalah 'the epistle of straw' atau surat remeh temeh. ${ }^{9}$

Dari uraian latar belakang masalah di atas, maka rumusan masalah dalam penelitian ini adalah sebagai berikut: Pertama, apa pandangan Rasul Paulus tentang Iman dan Perbuatan Iman dalam Roma 3:21-28 dan Efesus 2:8? Kedua, apa pandangan Rasul Yakobus tentang iman dan perbuatan iman dalam Yakobus 2:14-26? Ketiga, apa kesesuaian dan perbedaan pandangan Rasul Paulus dan Rasul Yakobus tentang iman dan perbuatan iman?

\section{B. METODOLOGI}

Oleh karena tujuan penelitian ini adalah menganalisis data kualitatif berupa tinjauan pustaka, maka metode penelitian yang digunakan adalah metode kualitatif. M. Junaidi mengatakan bahwa penelitian kualitatif menekankan pada quality atau hal terpenting suatu barang atau jasa. Hal terpenting yang dimaksud adalah makna di balik kejadian, fenomena, dan

\footnotetext{
${ }^{4}$ Jeremy T. Alder, The Relationship Between Faith and Works: A Comparison of James 2:24 and Ephesians 2:8-10 (Reformed Theological Seminary, 2005), 1.

${ }^{5}$ Peter H. Davids, Ucapan yang Sulit dalam Perjanjian Baru, terj. Fenny Veronica (Malang: SAAT, 2013), 161.

${ }^{6}$ Jeremy T. Alder, 1.

${ }^{7}$ Guy H. King, A Belief that Behaves: An Expositional Study of the Epistle of James (Fort Washington, PA: Christian Literature Crusade, 1941), 53

${ }^{8}$ Luke Timothy Johnson, The Letter Of James (Nashvile: Abingdon Press, 1998), 197.

${ }^{9}$ Sharyn Dowd, Faith That Works; Review And Expositor (2000), 195.
} 
gejala sosial yang dapat dijadikan pelajaran berharga bagi pengembangan konsep teori. ${ }^{10}$ J.R. Raco menjelaskan bahwa metodologi penelitian kualitatif adalah suatu pendekatan atau penelusuran untuk mengeksplorasi dan memahami suatu gejala sentral. Dan untuk mengetahui gejala atau fenomena sentral tersebut peneliti mewawancarai objek atau peserta yang diteliti dengan mengajukan pertanyaan-pertanyaan yang lebih luas. ${ }^{11}$ Oleh karena tujuan penelitian ini adalah menemukan hubungan teologis tentang iman dan perbuatan iman dari Teologi Paulus dan Teologi Yakobus. Maka dalam riset ini dipilih jenis riset studi biblika. Studi biblika adalah eksegesis (memahami makna teks) dan kajian Alkitab (menyelidiki Alkitab dan bagianbagiannya sebagai teks). Peneliti melakukan exegese untuk menemukan Teologi Paulus dan Teologi Yakobus tentang iman dan perbuatan iman, dan menemukan hubungan teologis kedua konsep teologi tersebut.

\section{PEMBAHASAN}

\section{Iman}

Iman tidak hanya sekedar pengertian intelektual atau suatu doktrin melainkan lebih dari itu, ada beberapa unsur dari iman diantaranya adalah: ${ }^{12}$

i). Unsur Intelektual-Kognisi

Bahwa iman melibatkan intelek dan menekankan bahwa ada kebenaran dasar tertentu yang harus dipercayai untuk keselamatan.

ii). Unsur Emosional - Afeksi

Bahwa keyakinan harus melibatkan emosibukan hanya kesadaran intelektual semata akan kebenaran-kebenaran melainkan secara batin/menjiwai hidup dan menghidupkan kebenaran Injil (Yoh. 16:8-11).

iii). Unsur Kehendak Manusia-Psikomotorik

Sebagai akibat dari pengetahuan atau kesadaranakan kebenaran Injil dan dengan teguh meyakininyamaka harus diwujudnyatakan dalam tindakan. "sebab jika kamu mengaku dengan mulutmu, bahwa Yesus adalah Tuhan, dan percaya dalah hatimu, bahwa Allah telah membangkitkan Dia dari antara orang mati, maka kamu akan diselamatkan."

Menurut Lois Berkhof iman memiliki tiga tingkatan, yaitu: ${ }^{13}$ Pertama, iman yang berarti rasa percaya yang menyeluruh kepada Tuhan Yesus. Kedua, iman yang berarti penerimaan akan kesaksian-kesaksian Firman oleh karena rasa percaya kepada Tuhan Yesus. Ketiga, iman yang berarti bersandar kepada Kristus dan beriman kepadaNya untuk keselamatan jiwa mereka. Hebrew Dictionary memberikan penjelasan tentang makna kata 'aman' yaitu bersandar pada sesuatu atau seseorang dengan penuh keyakinan. Dalam arti yang lain, 'aman' berarti mengikat hati yang mampu bertahan pada sabda janji Ilahi, bersandar pada kuasa dan

\footnotetext{
${ }^{10}$ M. Djunaidi Ghony dan Fauzan Almanshur, Metodologi Penelitian Kualitatif (Jogjakarta: ArRuzz Media, 2012), 25.

${ }^{11}$ Data-data yang dari objek penelitian berupa rekaman wawancara atau teks tertulis, kemudian dianalisis dan dideskripsikan secara lengkap. Dari data-data tersebut peneliti membuat interpretasi untuk menangkap makna terdalam dari data penelitian, dan kemudian menjabarkannya dengan hasil-hasil penelitian sebelumnya. Hasil akhir dari penelitian kualitatif kemudian dituangkan dalam bentuk laporan tertulis. J.R Raco, Metode Penelitian Kualitatif, (Grasindo), 7.

${ }^{12}$ Paul Enns, 87

${ }^{13}$ Lois Berkhof, 181-182.
} 
kesetiaan Allah. ${ }^{14}$ Iman dalam bahasa Ibrani juga ada yang menggunakan kata 'batakh' yang artinya percaya. ${ }^{15}$

Leon Morris menjelaskan bahwa iman adalah sikap yang di dalamnya seseorang melepaskan andalan pada segala usahanya sendiri untuk mendapatkan keselamatan. ${ }^{16}$ Dalam PB iman lebih ditujukan kepada Yesus, yaitu percaya bahwa Yesus adalah Tuhan, dan percaya kepada FirmanNya. Dalam kitab PB iman berarti mengamini dengan segenap kepribadian dan cara hidupnya, bahwa Yesus telah mendamaikan orang berdosa dengan Allah. ${ }^{17}$

Ellen G. White mengatakan bahwa tanpa iman adalah mustahil untuk dapat menyenangkan Allah, sebab setiap orang yang datang kepada Dia harus percaya bahwa Dia adalah Tuhan (Ibr. 11:6). ${ }^{18}$ Alkitab mengajarkan dengan jelas bahwa manusia yang berdosa "telah diselamatkan dengan cuma-cuma melalui "anugerah" (Roma 4:16). Jadi dasar pembenaran itu adalah kematian Kristus, dan sarana yang olehnya pembenaran itu menjadi efektif adalah iman.Akan tetapi, manusia harus merespon anugerah Allah tersebut bagi dirinya sendiri melalui iman.Melalui penjelasan tersebut, disimpulkan bahwa "karena anugerah oleh iman", Selanjutnya dinyatakan, "Sebab karena kasih karunia kamu diselamatkan oleh iman; itu bukan hasil usahamu, tetapi pemberian Allah, itu bukan hasil pekerjaanmu jangan ada orang yang memegahkan diri” (Efesus 2:8). Dikatakan 'jangan kamu memegahkan diri' artinya jangan kamu menyangka bahwa pekerjaan yang kamu kerjakan adalah suatu jasa melainkan semuanya adalah kasih karunia.

\section{Perbuatan Iman}

Ellen G. White dalam penjelasannya tentang perbuatan iman mengatakan bahwa orang percaya harus melakukan semua yang dapat dilakukan untuk pertarungan yang baik dari iman. Orang percaya harus bergulat, bekerja, berjuang, menderita untuk masuk di gerbang yang sesak itu. Allah telah menyediakan bantuan bagi orang percaya, yaitu Roh Kudus yang akan mempercepat dan memperbaharui orang percaya secara misterius. ${ }^{19}$ Dari ajaran Tuhan Yesus tampak bahwa keselamatan itu melalui iman yang akan tercermin dari perubahan gaya hidup. Yesus berkata kepada banyak orang bahwa: "Setiap orang yang mau mengikut Aku, ia harus menyangkal dirinya, memikul salibnya setiap hari dan mengikut Aku (Luk. 9:23). Pada bagian lain Tuhan Yesus berkata: Jika hidup keagamaanmu tidak lebih benar dari pada hidup keagamaan ahli-ahli Taurat dan orang-orang Farisi, sesungguhnya kamu tidak akan masuk ke dalam Kerajaan Sorga (Mat. 5:20). Pada bagian lain lagi Tuhan Yesus berkata: "Mengapa kamu berseru kepada-Ku: Tuhan, Tuhan, padahal kamu tidak melakukan apa yang Aku katakan? (Luk. 6:46).

\section{Exegesis Roma 3:21-28}

Paulus adalah seorang Yahudi yang lahir di Tarsus dari Kilikia, yang benar-benar terlatih dalam hukum di bawah Rabbi Gamaliel (Kis. 22:3). Jadi jelas bahwa teologi Paulus dipengaruhi oleh konsep Perjanjian Lama (PL). Oleh sebab itu perlu terlebih dahulu dipahami bagaimana sebenarnya pembenaran yang dipahami dalam PL, hal ini penting dalam upaya

\footnotetext{
${ }^{14}$ Hebrew Dictionary (www.searchGodSword.org)

${ }^{15}$ Leon Morris, Ensiklopedia Alkitab Masa Kini (Jakarta: Yayasan Komunikasi Bina Kasih, 2002), 430.

${ }^{16}$ Leon Morris, Ensiklopedia Alkitab Masa Kini, 431.

${ }^{17}$ Harun Hadiwijono, 18.

${ }^{18}$ Ellen G. White, Faith and Works (Washington DC: Ellen G. White Estate, 1979), 47.

${ }^{19}$ Ellen G. White, 48.
} 
memahami teologi iman seorang rasul Paulus. Menurut E. R. Achtemeier kitab PL menjelaskan bahwa kebenaran berbicara tentang pemenuhan tuntutan hubungan manusia dengan Allah. Ketika Allah atau manusia memenuhi persyaratan atau ketentuan yang dikenakan kepadanya oleh suatu hubungan, maka manusia itu benar dalam konsep PL. ${ }^{20}$

Konsep pembenaran ini jelas ditemukan beberapa peristiwa di kitab PL, , contohnya kisah Tamar (Kej. 38:26). Tamar dinyatakan saleh karena memenuhi tuntutan hukum levirate, ${ }^{21}$ sementara Yehuda gagal memenuhi hukum dengan tidak memberikan putranya yang ketiga kepadanya dalam perkawinan. ${ }^{22}$ Dalam hal ini terbukti bahwa Tamar disebut benar karena memenuhi hukum levirat. Jadi dalam PL seseorang dinyatakan benar atau adil, jika seseorang itu mematuhi hukum. Ide kebenaran PL adalah dasar bagi kebenaran Perjanjian Baru (PB),

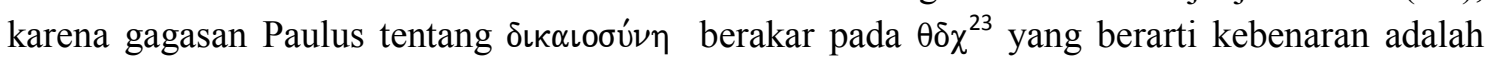
sesuai dengan aturan. ${ }^{24}$

Dalam Roma 1:18 hingga 3:20, ia berbicara tentang murka Allah dan penghakimanNya atas orang Yahudi dan bukan Yahudi; kemudian mulai dari 3:21, dia berbicara tentang bagaimana Tuhan menunjukkan kebenaranNya yang menyelamatkan di dalam Kristus. Wahyu murka Allah dalam 1:18 dijawab oleh kebenaran Allah yang menyelamatkan dalam pasal 3. ${ }^{25}$ James R. Edwards menulis, "'Tetapi sekarang' suatu seruan pengharapan yang menandai transisi dari murka (1:18) menjadi kebenaran (1:17)." Oleh karena itu, 3:21 menunjukkan transisi yang signifikan, kontras dengan apa yang Paulus katakan dalam 1: 18-3: 20. Jadi konteks ini menunjukkan kepada kita bahwa Paulus mengajarkan kebenaran Yahweh; Tindakan penyelamatannya digenapi dalam Yesus Kristus. ${ }^{26}$

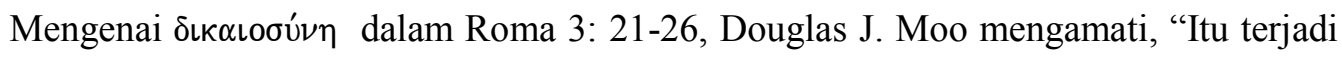
empat kali (ay. 21, 22, 25, 26 ['kebenarannya' dalam dua terakhir]), sementara yang terkait kata

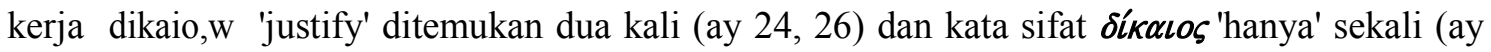
26). "27 Ada penafsiran tentang dikaiosu,nh qeou oleh beberapa pakar seperti J. Moo, James R. Edwards, Robert H. Mounance, and James Dunn yang menjelaskan bahwa kata tersebut dalam bentuk kata benda Genetif. ${ }^{28}$ Mereka berpendapat bahwa kebenaran adalah apa yang Allah tawarkan kepada orang berdosa, bahwa itu adalah tindakan Allah ketika Ia mengutus Yesus untuk mati bagi dosa dunia sehingga Ia dapat menyatakan kebenaran kepada siapa saja yang percaya pada Yesus. Argumen ini tampaknya agak lemah, karena kriteria apa yang dibenarkan Tuhan dipertanyakan. Sebagaimana dicatat di atas, orang-orang berdosa PL menjadi adil dan benar dengan menyesuaikan diri mereka dengan hukum yang ada. Dengan cara yang sama, orang-orang berdosa PB perlu dibenarkan dengan menyesuaikan dengan hokum yang ada.

${ }^{20}$ E.R Achtemeier, "Righteousness" in Interpreter's Dictionary of the Bible, ed. George Arthur Buttrick (Nashville, TN: Abingdon Press, 1962), 80.

${ }^{21}$ George Eldon Ladd, A Theology of the New Testament, rev. ed. D. A. Hagner (Grand Rapids, MI: William B. Eerdmans Publishing Company, 1993), 481.

${ }^{22}$ Norman H. Snaith, The Distinctive Ideas of the Old Testament (Philadelphia: The Westminster Press, n.d), 92-93.

${ }^{23}$ Achtemeier wrote, "The Septuagint frequently translates qydc with di,kaioj; qde (verb) with dikaiow; qde (noun) with dikaiosu,nh

${ }^{24} \mathrm{P}$. Van Imschoot, Theology of the Old Testament. Translated by Kathryn Sullivan, R. S.C.J. and Fidelis Buck, S, J. (Tournai: Desclee Company, 1954), 67.

${ }^{25}$ A.H. Leitch, "Righteousness," in The Zondervan Pictorial Encyclopedia of the Bible, ed. Merill Tennery (Grand Rapids: MI: Zondervan Publishing House, 1976), 113.

${ }^{26}$ A. H. Leitch, 114.

${ }^{27}$ Douglas Moo, 219.

${ }^{28}$ James R. Edwards, 100. 
Berbeda dengan pandangan Douglas Moo, penafsir lain seperti Brendan Byrne, C. K. Barrett, dan Leon Morris berpendapat bahwa dikaiosu,nh qeou menjelaskan kepribadian Allah, bahwa Dia adalah adil dan benar. ${ }^{29}$ Gagasan ini menyatakan bahwa Allah yang benar membenarkan orang berdosa sesuai dengan kebenaran-Nya. Dalam mendukung argumen ini, Charles Hodge menjelaskan bahwa "dikaiow untuk membenarkan "bukan hanya untuk mengampuni tetapi adalah istilah forensik yang mengekspresikan tindakan hakim." ${ }^{\text {"3 }}$ Pembenaran yang dimaksud dilakukan Yesus, dengan menjadikan dirinya sebagai korban kayu salib untuk membenarkan manusia berdosa. Dengan korban kayu salib, Yesus sebagai Anak Domba Allah memenuhi persyaratan untuk membenarkan manusia. Hal ini sesuai dengan kebenaran Allah sebagaimana yang dilakukan orang-orang dalam PL. Jadi siapa pun yang percaya kepada Yesus Kristus dibenarkan, dengan pembenaran korban kayu salib. Argumen ini lebih disukai dalam konteks khusus ini, karena kebenaran Allah berdiri sebagai kriteria yang dengannya Ia membenarkan orang berdosa.

Mounce berpendapat bahwa "Kebenaran yang Allah sediakan berasal dari apa yang Tuhan lakukan, bukan berasal dari apa yang dapat dilakukan manusia. Jadi pembenaran yang Yesus lakukan benar-benar terpisah dari ketaatn terhadap hukum. ${ }^{31}$ Pembenaran ini benar-benar

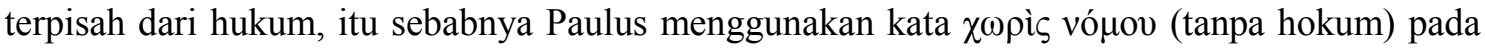
bagian awal ayat 21. Jadi penggunaan Paulus pada kata dwrean sesuai dengan bahasa Ibrani "סָּחִדִ yang menekankan bahwa kebenaran tidak didapatkan tetapi merupakan pemberian dari anugerah Allah. ${ }^{32}$

Kasih karunia Allah adalah hal yang penting, maksudnya bahwa Tuhan membuat keselamatan tersedia bagi orang-orang berdosa. Brendan Byrne dengan tepat berpendapat bahwa, "Kebenaran Allah adalah sesuatu yang sepenuhnya" terpisah dari hukum, "tidak didasarkan pada pemenuhan persyaratan hokum (ay. 20). ${ }^{33}$ Mounce lebih lanjut mengatakan bahwa, "tidak ada manusia yang dapat berada di bawah posisi yang benar bersama Tuhan, atas dasar melakukan apa yang dituntut hukum". ${ }^{34}$ Mengenai manusia, Edwards menjelaskan bahwa “sa.rx 'daging' (Rom. 3:20) menjelaskan bahwa orang berdosa tidak mampu hidup sesuai moral yang tepat di hadapan Allah, untuk memenuhi tuntutan hukum. Kondisi manusia yang telah jatuh ke dalam dosa mengharuskan penebusan Yesus untuk membawa manusia berada pada posisi benar (dibenarkan) di hadapan Allah.

Yesus mati untuk dosa dunia, dengan memenuhi standar kebenaran Allah ketika Ia menjadi korban kayu salib. Penyembelihan korban sesuai dengan sistem pengorbanan Ibrani. Kebenaran di hadapan Allah menuntut penumpahan darah Yesus agar orang berdosa dapat memiliki pengampunan atas dosa-dosa mereka (Ibrani 9:22). Jadi siapa saja yang percaya kepada Yesus diampuni, dibenarkan, dan bebas dari penghakiman karena pengorbanan Yesus

\footnotetext{
${ }^{29} \mathrm{C}$. K. Barrett wrote the righteousness of God "includes the quality of being right." See $A$ Commentary on the Epistle to the Romans (London: A \& C Black, 1991), 69; Leon Morris asserts that it is the righteousness which originates in God. See The Epistle to the Romans (Grand Rapids, MI: William B. Eerdmans Publishing Company, 1988), 103.

${ }^{30}$ Charles Hodge, Commentary on the Epistle to the Romans (Grand Rapids, MI: Wm. B. Eerdmans Publishing Company, 1974), 81-82.

${ }^{31}$ Mounce, Romans: The New American Commentary, vol. 27 (USA: Broadman \& Holman Publishers, 1995), 114.

${ }^{32}$ Terence E.Fretheim, New International Dictionary of Old Testament Theology \& Exegesis, vol. 2, ed. Willem A. VanGemeren (Grand Rapids, MI: Zondervan Publishing House, 1997),203

${ }^{33}$ Byrne, Romans: Sacra Pagina Series, vol. 6, ed. Daniel J. Harrington (Collegeville, MN: The Liturgical Press, 1996), 124.

${ }^{34}$ Mounce, $110-111$.
} 
tidak hanya memenuhi tuntutan kebenaran, tetapi juga meredakan amarah Allah. ${ }^{35}$ Jadi tidak ada kebenaran tanpa Yesus Kristus, karena "Dan Ia adalah pendamaian untuk segala dosa kita, dan bukan untuk dosa kita saja, tetapi juga untuk dosa seluruh dunia (1Yoh. 2:2).

Douglas J. Moo mengatakan bahwa, "Paulus menyoroti iman sebagai sarana yang dengannya pekerjaan pembenaran Allah menjadi berlaku bagi setiap individu". "Selain itu, Dunn berpendapat bahwa, "Iman adalah kondisi atau sikap manusia yang berbeda dengan perbuatan hukum ( Rom. 3: 20-22, 27-28). ${ }^{37}$ Dalam hal ini, jelas bahwa manusia hanyalah alat dosa dan tidak berdaya untuk bekerja demi keselamatannya sendiri. Dengan demikian, itu menuntut bahwa Allah menyatakan kebenaran-Nya kepada orang-orang berdosa.

Dalam perspektif pembenaran, Schafer mengatakan bahwa; "Tuhan tidak mengisi diri manusia dengan kebenaran, namun Tuhan membuat deklarasi resmi bahwa manusia dibenarkan melalui korban Kristus. ${ }^{38}$ Jadi pembenaran adalah deklarasi Allah pada setiap orang yang percaya karya penebusan yang Yesus telah kerjakan. Orang-orang Perjanjian Baru memahami dengan baik maksud dari perkataan Yesus, bahwa Ia datang untuk menggenapi hukum Taurat (Mat. 5:17). Kematian Yesus di kayu salib merupakan tindakan menggenapkan tuntutan hukum Taurat, yaitu menjadikan manusia berdosa menjadi benar sesuai dengan kriteria benar yang ditetapkan oleh Allah.

Jadi Paulus sangat menentang konsep bahwa pembenaran manusia disebabkan oleh perbuatan mentaati hukum Taurat. Menurut Paulus iman adalah hal yang sangat penting dalam hal keselamatan; "karena kami yakin bahwa manusia dibenarkan oleh iman, dan bukan karena ia melakukan hokum Taurat"(3:28). Paulus dalam konteks dekat sedang menegur keangkuhan orang Yahudi (bab 2-4)." Dia mengajarkan bahwa orang Yahudi membutuhkan keselamatan melalui melalui iman kepada Yesus. Inilah alasan Paulus menulis surat Roma agar gereja Roma memahami betapa besarnya rahmat Allah dan luasnya kemurahan Tuhan." 39

Paulus sebagai seorang Yahudi berlatar belakang Farisi, mengerti betul bahwa pembenaran Allah atas manusia adalah ketika manusia hidup sesuai dengan hukum Taurat. Namun penyataan wahyu Ilahi yang diterima rasul Paulus menjadikan dirinya memahami bahwa pembenaran datang melalui iman kepada Kristus. Paulus mengajarkan orang-orang percaya yang ada di Roma, bahwa iman kepada Yesus adalah finalitas pembenaran. Jadi penolakan Paulus terhadap 'perbuatan' sebagai dasar pembenaran, harus dipahami dalam konteks keyakinan Yahudi terhadap perbuatan hukum Taurat. Robertson mengatakan bahwa Paulus mempertentangkan iman dan perbuatan, dilatarbelakangi doktrin Yahudi bahwa pembenaran adalah kesesuaian hidup dengan hokum Taurat. ${ }^{40}$ Dengan demikian Paulus dengan jelas mengajarkan bahwa pembenaran hanya melalui iman, dan ini bertentangan dengan konsep Yahudi yang menuntut sunat sebagai dasar pembenaran orang-orang bukan Yahudi di Roma. Jadi Paulus tidak menentang perbuatan iman, tetapi menentang konsep yang menjadikan perbuatan manusia sebagai dasar pembenaran Allah atas manusia (Rom. 3:27).

${ }^{35}$ Charles Hodge, Romans: The Crossway Classic Commentaries (Wheaton, IL: Crossway Books, 1993), 89.

${ }^{36}$ Douglas J. Moo, 224.

${ }^{37}$ James D.G. Dunn, 166.

${ }^{38}$ Francis A. Schaeffer, The Truth of Romans 1-8: The Finished Work of Christ (Wheaton, Illinois: Crossway Books, 1998), 76.

${ }^{39}$ F. David and Ralph P. Martin, Romans In The New Bible Commentary (Grand Rapids: William B. Eerdmans Publishing Company, 1970), 1013.

Press, n.d.), 93

${ }^{40}$ A. T. Robertson, Studies in the Epistle of James (Nashville, Tennessee: Broadman 


\section{Exegesis Efesus 2:8-9}

Penulis surat ini adalah Paulus seorang Farisi, yaitu seorang Yahudi yang berpegang teguh pada Taurat dan tradisi Yahudi. Konsep keselamatan Farisi adalah ketaatan tanpa cacat terhadap hukum Taurat dan tradisi Yahudi. Atas dasar usaha menjalankan hukum Taurat "jangan ada padamu Allah lain", rasul Paulus dengan bangga menganiaya dan membunuh orang-orang yang menurutnya menduakan Yahwe, yaitu mereka yang menjadi pengikut Yesus. Paulus melakukan segala ketentuan Yahudi, dan ia tidak bercacat dalam mentaati hukum taurat, semua ini dihitung Paulus sebagai keuntungan rohani (Fil. 3:4-7a). Setelah Paulus bertobat dan mengalami kasih karunia Allah, Paulus oleh iluminasi Roh memiliki konsep baru dalam hal keselamatan. Paulus mengerti bahwa manusia diselamatkan bukan karena usaha baik manusia yang hina dan berdosa di pemandangan mata Allah, tetapi keselamatan adalah pemberian Allah yang tidak didasarkan pada kebaikan manusia yang berkualitas rendah itu. Kepada jemaat Efesus Rasul Paulus menunjukkan kesadaran rohani setelah pertobatannya, bahwa sebagai seorang yang memegang hukum Taurat dan seluruh tradisi Yahudi dengan tanpa cacat, sebenarnya ia adalah orang yang berdosa (Ef. 2:1-4). Kasih Allah yang besar atas Paulus yang memungkinkan dirinya beroleh keselamatan dari Allah.

Penerima surat ini adalah jemaat Efesus, dan Paulus sebelumnya telah melayani selama 3 tahun di jemaat Efesus dalam perjalanan misi pelayanannya yang ketiga. Pengetahuan Paulus tentang jemaat Efesus sepertinya tidak hanya didasarkan pada pengalaman tiga tahun yang lampau ketika melayani di Efesus. Paulus menerima informasi tentang keberadaan jemaat Efesus, itu sebabnya Paulus berkata; "aku mendengar tentang imanmu dalam Tuhan Yesus dan kasihmu kepada orang-orang Kudus " (Efesus 1:16b). Jadi Paulus sangat mengenal keberadaan dan masalah yang sedang dihadapi oleh jemaat Efesus. Pengalaman Paulus selama melayani di Efesus, selalu mendapatkan perlawanan dengan kelompok Yahudi, yang merasa pengajaran rasul Paulus bertentangan dengan keyakinan Yudaisme (Kis. 19, 20).

Paulus mengawali suratnya dengan menjelaskan betapa besar kasih Allah yang sedari awal telah merencanakan penyelamatan umatNya (1:4-11). Paulus ingin agar jemaat Efesus menjadi umat Allah yang benar, dimana Allah memberikan Roh Kudus sebagai jaminan memperoleh seluruh kepenuhan Kristus (1:12-14). Untuk menjadi umat yang benar, jemaat Efesus perlu mengenal pengharapan yang luar biasa dalam Kristus Yesus, itu sebabnya Paulus berdoa agar jemaat menerima Roh Kudus yang mampu mengajar umat tentang kehebatan kuasa dan kasih Allah (1:17-2:7).

Setelah Paulus menguraikan panjang lebar tentang kehebatan kuasa dan kasih Allah yang diperoleh orang percaya dalam Kristus Yesus, Paulus menjelaskan alasan mengapa Allah melakukan hal itu. Paulus mengawali penjelasan tentang alasan Allah itu dengan menggunakan

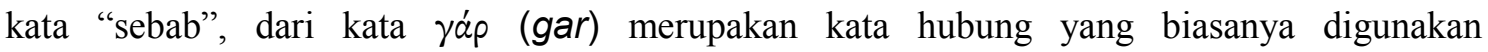
mengingatkan pembaca untuk berhenti sejenak dan merenungkan pernyataan selanjutnya. Kata ini juga digunakan untuk memberikan penjelasan mengenai suatu alasan. Paulus ingin menyampaikan suatu pesan yang penting untuk direnungkan mengenai alasan Allah menyatakan kuasa dan kasihNya yang luar biasa dalam Kristus.

Hal penting yang perlu direnungkan itu adalah pernyataan bahwa "dengan kasih karunia kalian adalah orang-orang yang telah diselamatkan melalui iman". Frasa "dengan kasih

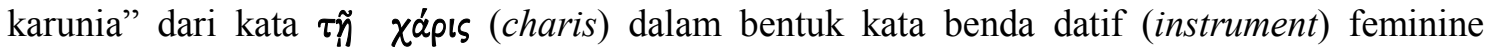
singular, oleh karena casenya adalah instrument yang artinya kata benda yang berfungsi sebagai keterangan alat maka kata ini lebih tepat diterjemahkan "dengan kasih karunia". Jadi sarana/alat yang Allah gunakan untuk menyelamatkan manusia adalah kasih karunia. 
TDNT menjelaskan bahwa kata'kasih karunia' secara umum berasal dari akar kata bermakna "joy atau rejoice" (kegembiraan atau bersukacita). Kata Charis digunakan untuk menunjukkan "niat baik" atau "kebaikan" para dewa dalam konteks kehidupan Yunani. Paulus menggunakan kata ini untuk menjelaskan "pemberian" Allah dalam karya penyelamatan manusia. Paulus menyebut Injil sebagai sarana kasih karunia Allah (Kol. 1:6). Dan dalam konteks yang paling dekat (Ef. 2:5; 3:2, 7-8; 4:7, 29), kata charis berarti "kebaikan" Allah yang ditunjukkan dalam Kristus. ${ }^{41}$ Jadi dapat disimpulkan bahwa makna 'kasih karunia' yang berperan sebagai sarana penyelamatan manusia yang dimaksud Paulus adalah pemberian Kristus Yesus atas dasar kebaikan (sukacita) Allah untuk menyelamatkan umat.

Jemaat Efesus yang terindikasi sedang mengalami kegoncangan iman mengenai Yesus sebagai satu-satunya sarana penyelamatan manusia, hal ini nampak dari uraian Paulus yang panjang lebar tentang keutamaan Kristus (Ef. 2:1-3:12). Konsep keselamatan lain di luar Yesus, yang didengungkan oleh orang Kristen Yahudi telah menimbulkan kekacauan dalam jemaat Efesus yang non Yahudi. Bahkan beberapa jemaat Yahudi memegahkan diri oleh karena memegang hukum Taurat, dan meyakini pasti diselamatkan oleh karena usahanya mentaati hukum Taurat. Paulus menjawab masalah ini dengan pesan penting untuk direnungkan, yaitu bahwa sarana yang Allah tentukan untuk menyelamatkan manusia adalah Yesus Kristus. Hal ini sangat berkaitan dengan frasa selanjutnya, yaitu "oleh iman" yang arti sebenarnya adalah 'through faith' (melalui iman kepada Yesus).

Jemaat Efesus sedang meragukan bahwa Yesus adalah satu-satunya sarana penyelamatan manusia. Jemaat Efesus yang terdiri dari orang Yahudi dan non Yahudi, hal ini melatari munculnya masalah ajaran sesat. Pemikiran Yahudi mengenai keselamatan sangat mewarnai konsep keselamatan orang Kristen Yahudi di jemaat Efesus. Orang Yahudi menyakini bahwa keselamatan manusia hanya mungkin dengan ketaatan terhadap hukum Taurat dan sunat. Jadi pemikiran orang Kristen Yahudi pada masa itu, bahwa seseorang hanya mungkin diselamatkan jika orang tersebut percaya kepada Yesus dan juga melaksanakan segala ketetapan dalam Taurat Musa.

Kata "diselamatkan" dari kata $\sigma \varepsilon \sigma \omega \sigma \mu \varepsilon ́ v o r$ (sesosmenoi) dalam bentuk perfect passive pasrticiple, yang artinya menunjukkan suatu kegiatan yang telah terjadi sekali dan selesai dimana akibat dari kegiatan kata kerja tersebut masih berlaku sampai saat penulis mengatakannya (masa present penulis). Friberg Lexicon menerjemahkan kata ini 'bring to salvation' (membawa kepada keselamatan). Kata kerja "diselamatkan" menjelaskan suatu peristiwa penyelamatan di masa lampau yang sekali dan selesai terjadi, ini merupakan peritiwa Tuhan Yesus di kayu salib (waktu terjadinya sebelum jemaat Efesus berdiri). Akibat dari penyelamatan melalui penyaliban Yesus yang sekali dan tuntas itu, masih berlaku sampai saat Paulus menyampaikan pada jemaat Efesus. Jemaat Efesus yang dahulu sebagai penyembah berhala (Ef. 2:1-2) dan Paulus sebagai hamba dosa (Ef. 2:3), melalui sarana salib Kristus orang percaya telah dibawa kepada keselamatan atau suatu kehidupan yang baru (Ef. 2:5, 10).

Pada bagian selanjutnya Paulus menasehati agar setiap orang percaya tidak boleh memegahkan kerohanian diri sendiri, sebab alasan manusia diselamatkan adalah "korban kayu salib". Penyelamatan manusia adalah inisiatif dari Allah bukan atas dasar usaha manusia. Paulus yang pernah melayani di Efesus selama tiga tahun, memahami persis bahwa jemaat Efesus dapat dipengaruhi oleh kelompok Yahudi yang memegahkan diri karena berpikir diselamatkan oleh ketaatan terhadap hukum Taurat.

\footnotetext{
${ }^{41}$ Theology Dictionary of New Testament, 1304.
} 
Untuk melengkapi konsep penting ini (“dengan kasih karunia kalian diselamatkan melalui iman"), Paulus menegur jemaat yang meyakini bahwa manusia diselamatkan karena manusia itu melakukan hukum. Kata "pekerjaanmu" dari kata épyov (ergon) dalam bentuk genetif neuter plural dengan penambahan preposition $\dot{\varepsilon} \xi$ yang memberi penambahan kata sandang "berasal dari" pada makna kata ergon. Kata ergon sendiri memiliki arti hasil pengerjaan seseorang, tentang melakukan hukum Taurat. ${ }^{42}$

Dengan demikian Paulus sedang menegaskan kepada jemaat Efesus bahwa orang percaya diselamatkan Allah dengan sarana "korban kayu salib", dan bukanlah karena usaha manusia menuruti hukum Taurat. Sebab itu tidak ada alasan bagi jemaat Efesus untuk memegahkan diri karena melakukan hukum Taurat. Kata "memegahkan diri" dari kata

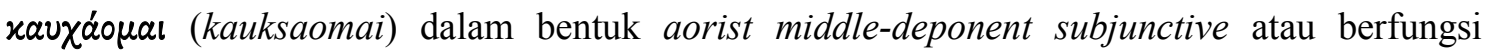
sebagai kata kerja aktif kemungkinan besar segera terjadi. Kata kauksaomai digunakan untuk mengungkapkan tingkat kepercayan diri yang sangat tinggi pada seseorang. ${ }^{43}$ Makna lain dari kata kauksaomai adalah tindakan yang bernuansa buruk dalam memuliakan sesuatu.

Paulus seringkali menunjukkan sikap bertentangan pada orang-orang yang bermegah diri karena meyakini bahwa keselamatan adalah hasil dari upaya manusia semata dalam mentaati hukum. ${ }^{44}$ Paulus menjelaskan bahwa orang yang beriman tidak akan memegahkan diri (Rom. 3:27). Abraham sebagai bapa orang percaya sekalipun tidak bersikap memegahkan diri (Rom. 4:2). Orang-orang Yudaisme memegahkan dirinya oleh kesanggupannya mentaati hukum taurat, dan Allah memandang sikap ini sebagai kemegahan yang keliru terhadap hukum Taurat (Rom. 2:17, 23).

\section{Exegesis Yakobus 2:14-26}

James T. Draper mengatakan bahwa Yakobus menulis suratnya kepada gereja yang tercerai-berai, yang melewati pencobaan dan ujian. ${ }^{45}$ Jemaat yang menerima tulisan Yakobus ini adalah orang-orang Kristen Yahudi yang telah melarikan diri dari Palestina ke lingkungan orang-orang bukan Yahudi. ${ }^{46}$ Draper berpendapat bahwa Yakobus mendefinisikan perbuatan iman seperti melakukan amal Kristen karena ada orang miskin (2: 16-17) di komunitas Kristen Yahudi. Jadi, dalam suratnya Yakobus berurusan dengan masalah pengabaian orang miskin. Robertson berpendapat bahwa, "Antitesis dalam Yakobus tidakantara iman dan perbuatan, tetapi antara iman yang hidup dan iman yang mati." OLeh karenanya Yakobus menyakal ajaran sesat yang mengklaim bahwa keselamatan tidak memiliki hubungan dengan bagaimana cara hidup atau perbuatan iman. Jadi iman yang hidup tidak akan berdiri dengan tangan yang terlipat dihadapan orang miskin, tetapi senang melakukan kebaikan untuk mereka yang membutuhkan. Jadi Yakobus sebenarnya tidak bertujuan mengajarkan bahwa perbuatan manusia menghasilkan keselamatan, tetapi perbuatan adalah buah dari iman atau ketaatan kepada Allah. ${ }^{47}$

Yakobus 2: 14-26 menyatakan, "Apakah gunanya, saudara-saudaraku, jika seorang mengatakan, bahwa ia mempunyai iman, padahal ia tidak mempunyai perbuatan? Dapatkah iman itu menyelamatkan dia?" (ay 14). Selanjutnya Yakobus menyatakan, "Bukankah Abraham, bapa kita, dibenarkan karena perbuatan-perbuatannya, ketika ia mempersembahkan Ishak, anaknya, di atas mezbah?" (ay 21). Sekilas memperhatikan ayat-ayat di atas, memberi

\footnotetext{
${ }^{42}$ Thayer Greek Lexicon

${ }^{43}$ Louw Nida Lexicon

${ }^{44}$ TDNT, 425.

${ }^{45}$ James T. Draper, Faith That Works (Wheaton: Tyndale House Publisher, 1971), 12.

${ }^{46}$ A.T Robertson, Studies In The Ephistle of James (Nashvile: Broadman Press, tt), 28.

${ }^{47}$ James T. Draper, 87
} 
kesan bahwa diperlukan usaha manusia dalam memperoleh keselamatan atau bukan karena anugerah saja.

Charles F. Pfeifer dan Everent F. Harrison menyatakan, "Jawaban yang diharapkan dari pertanyaan dalam ayat ini adalah "tidak" yang tegas.Mengapa? Karena penting untuk dicatat bahwa iman yang dibahas di sini adalah iman yang palsu. Hal ini di jelaskan oleh: (1) pernyataan jika seorang mengatakan bahwa ia mempunyai iman dan (2) pemakaian kata sandang tertentu yang digabungkan dengan kata iman pada anak kalimat terakhir. Hanya iman palsu yang tidak dapat menghasilkan perbuatan dan tidak mampu menyelamatkan. ${ }^{48}$

Yakobus menulis suratnya untuk mendorong dan menasihati orang-orang Yahudi yang telah melarikan diri dari penganiayaan di Yerusalem, dan tinggal di luar Palestina. ${ }^{49}$ Yakobus menegur orang Yahudi Kristen agar tetap kuat dalam iman; dan pada saat yang sama, ia mendesak orang-orang kaya untuk tidak mengabaikan rekan-rekan Kristen mereka yang miskin. Dalam konteks ini, Yakobus sedang menasehati perihal tentang "iman statis", karena orang Kristen Yahudi tidak menunjukkan kepeduliaannya kepada sesame jemaat Kristen Yahudi yang miskin. Yakobus dengan tegas mendorong orang Yahudi Kristen untuk menjadi pelaku Firman. ${ }^{50}$

Martih dalam tafsirannya menjelaskan bahwa Yakobus 2:14-26 ini adalah penilaian Yakobus tentang bahaya dari sikap menipu diri sendiri. ${ }^{51}$ Menurut Douglas J. Moo bahwa pada bagian ini Yakobus sedang menegaskan, bahwa ia memerangi beberapa guru palsu yang menetapkan pandangan iman yang salah. ${ }^{52}$ Dalam bagian ini kata $\pi\llcorner\sigma \iota \varsigma$ (pistis) 'iman' hanya

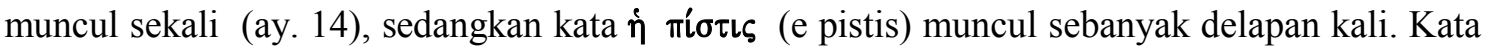
pistis tanpa definitive artikel $\dot{\eta}$ memperkenalkan suatu ide yang baru. ${ }^{53}$ Donal $\mathrm{W}$. Burnick dan Simon J. Kistemaker sepakat bahwa ada dua pertanyaan retoris yang Ironis muncul dalam ay. 14, yang pertama adalah pertanyaan tentang 'kegunaan iman'. Kata pistis iman pada pertanyaan pertama tidak menggunakan definitive artikel, sehingga tidak merujuk pada iman yang sejati. Pertanyaan retorika kedua yang membutuhkan jawaban negative menggunakan kata iman (memakai definitive artikel), untuk menjelaskan kata iman pada pertanyaan retorika pertama. ${ }^{54}$

Jadi kata pistis dalam ayat 14a didefinisikan oleh Martin sebagai iman yang tidak berguna untuk keselamatan, sedangkan e pistis pada ayat 14b mengacu pada 'iman yang tidak berguna' seperti pada ayat $14 \mathrm{a} .{ }^{155}$ Yakobus menambahkan bahwa iman yang berprilaku seperti ilustrasi pada ayat 15-16a adalah iman yang tidak berguna bagi keselamatan. ${ }^{56}$ Dengan Mas, 2001)

${ }^{48}$ Charles F. Pfeifer dan Everent F. Harrison, Tafsiran Alkitab Wycliffe (Malang: Gandum

${ }^{49}$ Douglas Moo, James In Evangelical Commentary On The Bible (Grand Rapids: Baker Book House, 1989), 1151.

${ }^{50}$ Ronald A Ward, James In The New Bible Commentary (Grand Rapids: William B. Erdmans Publishing Comapany, 1970), 1222.

${ }^{51}$ Ralp P.Martin, “James: Word Biblical Commentary (Waco TX, Word Book Publisher, 1988), 79.

${ }^{52}$ Douglas J Moo, The Letter of James: The Tyndale New Testament Comentaries (Grand Rapids: William B. Erdmans Publishing Comapany, 1985), 99.

${ }^{53}$ James Hardy Ropes, A Critical And Exegeticxal Commentary on The Ephistle Of St. James (Endinburgh: T \& T Clark, 1991), 203.

${ }^{54}$ Donald W. Burdick, James In The Espositor's Bible (Grand Rapids: Zondervan Pblishing House, 1981), 182. Kistemaker, New Testament Commentary (Grand Rapids: Baker Book House, 1986), 87.

81.

${ }^{55}$ Ralp P.Martin, “James: Word Biblical Commentary (Waco TX, Word Book Publisher, 1988),

\footnotetext{
${ }^{56}$ Ralp P.Martin, 80.
} 
memperhatikan ayat 14-16a dapatlah dipahami bahwa pistis tanpa definitive artikel bertujuan memperkenalkan 'iman yang mati' sebagai lawan dari iman yang otentik atau hidup, seperti halnya Abraham dan Rahab. Jadi sebenarnya pertanyaan retorika kedua berbunyi 'dapatkan iman yang mati menyelamatkan'? Jawabannya bahwa "iman yang mati" seperti pada konteks ini tidak dapat menyelamatkan.

Penggunaan kata legh 'mengatakan' dalam ayat 14 menunjukkan suatu pernyataan yang berulang-ulang; kata ini menjelaskan bahwa ada orang yang terus-menerus memperkatakan dirinya memiliki iman (iman yang mati), tetapai terus tidak memiliki perbuatan iman. Dengan demikian orang ini tidak pernah termotivasi untuk bertindak sesuai dengan apa yang menjadi imannya. Iman yang dimilikinya tidak pernah memotivasi dirinya untuk melakukan atau menghasilkan tindakan tertentu. ${ }^{57}$

Morris mengatakan Yakobus jelas sedang menghadapi orang-orang Kristen tertentu yang berpegang teguh bahwa yang penting hanyalah percaya. ${ }^{58}$ Tentu saja mereka mengatakan bahwa selama mereka memiliki iman, tidaklah menjadi soal bagaimana cara mereka hidup. Yakobus sangat menentang hal ini. Jenis iman yang ia tolak ini adalah jenis iman yang sama yang dimiliki oleh setan-setan (2:19). Dalam Yakobus 2:19, penulis memberikan pengertian yang jelas mengenai apa yang dimaksudkan dengan "iman". Pernyataan di dalam ayat ini bukan hanya merupakan keyakinan agama Yahudi (Ul. 6:4), melainkan juga kebenaran tentang Allah yang diyakini bangsa Yahudi telah ditemukan oleh Abraham. Hal ini merupakan ortodoksi, yang juga dimiliki oleh iblis. ${ }^{59}$ Mereka percaya kepada Allah, namun apa yang dihasilkan oleh iman itu tidak lebih dari kegentaran saja. ${ }^{60}$ Iman jenis ini yang berkata kepada orang yang berkekurangan, "Selamat jalan, kenakanlah kain panas dan makanlah sampai kenyang!" tetapi tidak berbuat apa-apa untuk mencukupi kebutuhan orang tersebut (2:15-16). Dengan kata lain, iman yang dimaksudkan dalam Yakobus 2:14-26 merupakan ortodoksi tanpa adanya tindakan.

Bagi Yakobus, pernyataan kebenaran yang sesungguhnya dalam Kejadian 22:12 menunjukkan bahwa iman yang disebutkan dalam Kejadian 15:6 bukan semata-mata ortodoksi, melainkan keyakinan yang mengarah pada perbuatan yang nyata. Sehingga "iman bekerja sama dengan perbuatan-perbuatan dan oleh perbuatan-perbuatan itu, iman menjadi sempurna" (Yak. 2:22). ${ }^{61} \quad$ Yakobus memakai contoh bagaimana Abraham mengorbankan Ishak, untuk menunjukkan bahwa iman harus diwujudkan dalam perbuatan agar menjadi nyata (2:21-24). Yakobus ingin memperingatkan orang-orang yang mengatakan bahwa mereka memiliki hubungan yang benar dengan Allah atas dasar ortodoksi mereka, tetapi mengabaikan masalah ketaatan khususnya kemurahan hati. Jadi, iman yang dimaksudkan Yakobus tidak sama dengan Paulus yang menunjuk sikap penyerahan diri orang berdosa, karena tidak dapat mengandalkan apa pun kecuali anugerah Allah. ${ }^{62}$

Dalam nats ini Yakobus prihatin atas manusia yang menyatakan diri beriman tetapi tidak memperlihatkan buktinya dalam perbuatan belas kasihan. Setiap kebenaran dapat diputar balikkan, dan doktrin tentang keselamatan oleh iman dapat dengan mudah diselewengkan

${ }^{57}$ Ralp P.Martin, 80 .

${ }^{58}$ Leon Morris, Teologi Perjanjian Baru (Malang: Gandum Mas, 2001), 434.

${ }^{59}$ Peter H. Davids, Ucapan yang Sulit dalam Perjanjian Baru, terj. Fenny Veronica (Malang: SAAT, 2013), 160.

${ }^{60}$ Morris, Teologi Perjanjian Baru, 435.

${ }^{61}$ Davids, Ucapan yang Sulit, 161.

${ }^{62}$ Hasan Sutanto, Surat Yakobus: Berita Perdamaian yang Patut Didengar (Malang: SAAT, 2006), 258. 
menjadi pengakuan suatu kepercayaan tanpa diimbangi oleh kekudusan hidup. ${ }^{63}$ Bila Yakobus menyebut "perbuatan", yang dimaksudkan bukanlah perbuatan yang merupakan pencobaan memenuhi hukum Taurat semata, melainkan kebajikan dan pemberian sedekah. ${ }^{64}$ Perbuatan yang didorong oleh kasih seseorang kepada sesamanya, bukan untuk memperoleh keselamatan. Pada dasarnya Paulus memakai kata "perbuatan" untuk menunjuk hal-hal yang berkaitan dengan hukum ritual, sedangkan Yakobus menunjuk hal-hal yang berkaitan dengan kasih dan belas kasihan $(2: 7,13){ }^{65}$

Jadi, Yakobus tidak menyangkal pentingnya iman, ia hanya menekankan bahwa iman itu lebih dari sekedar intelektualisme kosong. ${ }^{66}$ Ia bukannya menentang pembenaran melalui iman, tetapi ia mengecam kemunafikan mereka yang berpura-pura memiliki iman tanpa menunjukkannya dalam perbuatan (2:18). Ia justru setuju dengan pemahaman Paulus bahwa pembenaran hanya melalui iman yang diterapkan dalam kehidupan sehari-hari (justification by faith, not by works).

Menurut JA. Motyer, Yakobus memiliki 2 penjelasan tentang percaya atau keyakinan yaitu keyakinan pikiran dan keyakinan hati (ay. 19 dan 23-24). Iman pada pikiran atau iman yang statis hanya berbuahkan ketakutan, sedangkan iman pada hati berbuahkan perbuatan seperti iman Abraham. Jadi ketika Yakobus mengatakan bahwa 'bukan hanyak karena iman' (ay. 24), iman yang dimaksud disini adalah keyakinan pikiran atau iman yang statis. ${ }^{67}$ Iman pada pikiran saja adalah iman statis yang tidak dapat menganugerahkan keselamatan. Iman pada pikiran juga digambarkan sebagai 'iman iblis' (Mar. 1:24-27), yaitu iman yang tidak memotivasi iblis untuk mencintai dan menyembah Tuhan (Mat. 4:10-11).

Demikian juga setiap orang yang mengaku memiliki iman, namun tidak memiliki motivasi untuk melakukan perbuatan iman, maka imannya hanyalah keyakinan pada pikiran saja atau iman yang mati. Richardson menjelaskan bahwa Yakbus sedang tidak menjelaskann bahwa perbuatan manusia menganugerahkan keselamatan, tetapi iman yang hidup yang tampak dari perbuatannnya adalah iman menganugerahkan keselamatan. Jadi perbuatan iman menunjukkan keabsahan iman. ${ }^{68}$ Tepat apa yang dikatakan Burdick, bahwa iman adalah sikap dari manusia batiniah, karena itu mempengaruhi tindakan orang yang memilikinya. ${ }^{69}$

\section{KESIMPULAN}

Berdasarkan kajian yang dilakukan tentang, apa sebenaranya pandangan Rasul Paulus mengenai Iman dan Perbuatan Iman dalam Roma 3:21-28 dan Efesus 2:8. Hasil penelitian menunjukkan bahwa Paulus mengabarkan Injil kepada bangsa-bangsa Yahudi dan non-Yahudi, yang sangat membanggakan hukum Taurat. Ketika Paulus mengatakan seorang dibenarkan oleh iman, yang dimaksudkannya adalah tidak ada yang dapat diandalkan manusia untuk dibenarkan di depan Allah. Paulus menghadapi dua situasi yang berbeda: Paulus menghadapi pembenaran diri ibadah Yahudi legal dan Yakobus menghadapi ortodoksi yang mati. ${ }^{70}$ Paulus berpendapat bahwa keselamatan tersedia karena tindakan Allah, bukan karena jasa manusia, bahwa

\footnotetext{
${ }^{63}$ Merrill C. Tenney, Survei Perjanjian Baru (Malang: Gandum Mas, 1985), 328.

${ }^{64}$ Guthrie, Teologi Perjanjian Baru, 132.

${ }^{65}$ Hasan, Surat Yakobus, 258.

${ }^{66}$ Morris, Teologi Perjanjian Baru, 436.

${ }^{67}$ J.A. Motyer, The Message Of Jammes (Leceister: Inter Varsity Press, 1997), 112.

${ }^{68}$ Richardson, 129.

${ }^{69}$ Burdick, 183.

${ }^{70}$ Ladd, Teologi Perjanjian Baru, 404.
} 
keselamatan diperoleh karena iman, dan bahwa orang harus hidup sesuai dengan keselamatannya yaitu dalam hidup kudus.

Berdasarkan kajian yang dilakukan tentang, apa sebenaranya pandangan Rasul Yakobus mengenai Iman dan Perbuatan Iman dalam Yakobus 2:14-26. Hasil penelitian menunjukkan bahwa Yakobus sedang menghadapi konteks jemaat, dimana Ia berjuang mendamaikan kelompok kaya dan miskin dalam komunitas Yahudi. Yakobus melihat hal iman dan perbuatan iman adalah hal yang saling terkait. Yakobus memahami bahwa seorang yang telah mengaku memiliki iman, harus membuktikannya dengan perbuatan sehari-hari. Yakobus menasehati para pembacanya untuk menampakkan kasih persaudaraan. Guthrie menyebut pemahaman ini merupakan pemahaman yang dangkal terhadap Yakobus. ${ }^{71}$ Jenis perbuatan yang dimaksudkan Yakobus ialah perbuatan yang berasal dari iman yang sejati. Yakobus tidak mendukung pandangan yang menyatakan bahwa manusia dapat memperoleh keselamatan melalui perbuatannya. Tetapi ia justru memperingatkan setiap orang yang mengaku telah beriman harus diaplikasikan dalam kehidupan sehari-hari, dan peringatan ini juga dilakukan oleh Yesus kepada orang Farisi dan ahli Taurat seperti yang telah dijelaskan di atas

Berdasarkan kajian yang dilakukan tentang kesesuaian dan perbedaan pandangan Rasul Paulus dan Rasul Yakobus tentang iman dan perbuatan iman, maka disimpulkan temuan penelitian sebagai berikut. Ajaran Yakobus (2:14-26) tidak bertentangan dengan ajaran yang dituliskan Paulus (Rm. 3:21-30; 4:1-8; Gal. 2:16; Ef. 2:8-9, dsb.). Setelah memperhatikan Teologi Yakobus dan Paulus tentang iman dan perbuatan, peneliti menemukan perbedaan maksud yang disampaikan oleh kedua rasul besar ini. Hal ini seperti dua sisi mata koin, dimana Paulus mengamati satu sisi mata koin yaitu 'iman' dan Yakobus melihat sisi lainnya yaitu 'perbuatan iman'. Martin mengatakan bahwa Yakobus berusaha menjelaskan sisi aktif iman, sedangkan Paulus sedang menjelaskan sisi pasif iman. ${ }^{72}$ Jadi Paulus sedang berbicara kepada jemaat di Roma tentang awal memulai kehidupan Kristen yaitu iman kepada Yesus (Rom. 3:28), dimana melalui iman manusia dibenarkan tanpa ada kaitannya dengan perbuatan taat pada hokum Taurat (Gal. 2:16).

Berbeda dengan Yakobus yang sedang menasehati orang-orang Kristen Yahudi yang telah lama percaya (bukan pengikut Kristen yang baru), yang mengaku telah jatuh ke dalam cara-cara hidup yang salah dan sedang membutuhkan iman yang tulus. ${ }^{73}$ Tidak ada keraguan bahwa Yakobus dan Paulus oleh pimpinan Roh Kudus sedang menggiring jemaat kepada keKristenan yang murni dan sehat. Cara Yakobus memandang kisah Abraham bertujuan menunjukkan bagaimana iman yang sejati bekerja. Sedangkan Paulus melihat kisah Abraham untuk menunjukkan bagaimana Allah cenderung mengampuni orang-orang berdosa. Jadi jelas bila Paulus lebih fokus pada paparan tentang pembenaran oleh iman, sementara Yakobus memperhatikan perbuatan yang dihasilkan oleh iman sejati. Jadi Yakobus sebenarnya sedang tidak menentang konsep iman Paulus, demikian juga Paulus tidak sedang membantah konsep perbuatan yang disampaikan oleh Yakobus. Kemudia Yakobus dengan tegas mengutuk orangorang yang mati imannya, seperti Paulus yang mengutuk keyakinan orang-orang Kristen bahwa perbuatan hokum sebagai dasar pembenaran.

Demikian juga ketika Yakobus berbicara tentang pembenaran oleh perbuatan, bukan karena iman (Yak. 2:24). Yakobus ingin menejelaskan bahwa pembenaran tidak mungkin terjadi bila tidak memiliki iman yang sejati, dan iman yang sejati atau hidup itu tampak dari perbuatannya.

\footnotetext{
${ }^{71}$ Ibid., 244.

${ }^{72}$ Ralph P. Martin, “James: Word Biblical Commentary, vol. 48 (Waco, TX: Word Books, Publisher, 1988), 82.

${ }^{73}$ Richardson, 140.
} 
Yakobus tidak sedang berbeda pandangan dengan Paulus mengenai jenis iman yang olehnya manusia dibenarkan.

\section{DAFTAR PUSTAKA}

Achtemeier, E. R. "Righteousness." In Interpreter's Dictionary of the Bible, edited by George Arthur Buttrick. Nashville, TN: Abingdon Press, 1962.

Barrett, C. K. A Commentary on the Epistle to the Romans. London: A \& C Black, 1991.

Black, Matthew. Romans: New Century Bible Commentary, $2^{\text {nd }}$ ed. Grand Rapids, MI: Wm. B. Eerdmans Publishing Company, 1973.

Burdick, Donald W. “James.” In The Expositor's Bible Commentary, vol. 12. ed. Frank E. Gaebelein. Grand Rapids, MI: Zondervan Publishing House, 1981.

Byrne, Brendan. Romans: Sacra Pagina Series, vol. 6. ed. Daniel J. Harrington. Collegeville, MN: The Liturgical Press, 1996.

Carson, T. "James." In The International Bible Commentary, eds. F.F. Bruce, H. L. Ellison and G. C. D. Howley. Grand Rapids, MI: Zondervan Publishing House, 1986.

Cranfield, C. E. B. A Critical and Exegetical Commentary on the Epistle to the Romans, vol. 1. New York, NY: T \& T Clark, 1975.

Dalton, Adele Flower. "How Pentecost Reached Burma," Mountain Movers, (September 1980): 1-16.

David, F. and Ralph P. Martin, "Romans" In The New Bible Commentary, $3^{\text {rd }}$ ed. Grand Rapids, MI: William B. Eerdmans Publishing Company, 1970.

Davids, Peter H. Ucapan yang Sulit dalam Perjanjian Baru, terj. Fenny Veronica, Malang: SAAT, 2013.

Morris, Leon. The Epistle to the Romans. Grand Rapids, MI: William B. Eerdmans Publishing Company, 1988.

Motyer, J. A. The Message of James: The Test of Faith (Leicester: Inter-Varsity Press, 1985.

Mounce, Robert H. Romans: The New American Commentary, vol. 27. USA: Broadman \& Holman Publishers, 1995.

Nawni, Khaung. The History and Growth of the Churches in Chin State. Th.M. thesis, Fuller Theological Seminary, 1990.

Nystrom, David P. James: The NIV Application Commentary. Grand Rapids, MI: Zondervan Publishing House, 1997.

Pauck, Wilhelm. Trans., and ed. Luther: Lectures on Romans. Philadelphia: The Westminster Press, n.d.

Pe, Hla. Burma: Literature, Historiography, Scholarship, Language, Life, and Buddhism. Singapore: Institute of Southeast Asian Studies, 1985.

Perkins, Pheme. "James." Interpretation: First and Second Peter, James, and Jude. Louisville: John Knox Press, 1995.

Richardson, Kurt A. James: The New American Commentary, vol. 36. U.S.A: Broadman \& Holman Publishers, 1997.

Robertson, A. T. Studies in the Epistle of James. Nashville, TN: Broadman Press, n.d.

Ropes, James Hardy. A Critical and Exegetical Commentary on the Epistle Of St. James. Edinburgh: T. \& T. Clark, 1991.

Shedd, William G. T. A Critical and Doctrinal Commentary on the Epistle of St. Paul to the Romans. Minneapolis, MN: Klock \& Klock Christian Publishers, 1978.

Sidebottom, E. M. The New Century Bible Commentary: James, Jude, 2 Peter. Grand Rapids, MI: Wm. B. Eermans Publising Company, 1967. 